Однак, незважаючи на поширення й унікальні можливості для навчання, дані технології доволі часто ігноруються офіційними органами системи освіти або ж забороняються взагалі. Оскільки сучасні учні практично не уявляють свого життя без смартфонів (спілкування в соціальних мережах, перегляд фільмів, розваги, пошук потрібної інформації, прослуховування музики тощо), залучення технологій із використанням мобільного пристрою під час уроків додатково заохотить школярів до вивчення будь-якого предмета.

\section{СПИСОК ВИКОРИСТАНОЇ ЛІТЕРАТУРИ}

1. Бузько В. Л. Можливості використання QR-кодів у навчанні фізики / В. Л. Бузько, Ю. В. Счкало // Наукові записки [Кіровоградського державного педагогічного університету імені Володимира Винниченка]. - 2016. Вип. 10 (1). - С. 112-118. - (Серія «Проблеми методики фізико-математичної і технологічної освіти»).

2. Вікіпедія. URL: https://uk.wikipedia.org/ (дата звернення: 16.01.2020)

3. Інтернет-ресурс зі створення QR-кодів. URL: http://www.qr-code-generator.com/ (дата звернення: 16.01.2020).

4. Інтернет-ресурс зі створення QR-кодів. URL: https://qr.net/ (дата звернення: 16.01.2020).
5. Інтернет-ресурс зі створення QR-кодів (українською мовою). URL: http://ua.qr-code-generator.com/ (дата звернення: 16.01.2020).

6. Інтернет-ресурс зі створення QR-кодів. URL: http://qrcode.tec-it.com/ru (дата звернення: 16.01.2020).

7. Інтернет-ресурс зі створення QR-кодів. URL: http://www.visualead.com/qr-code-generator (дата звернення: 16.01.2020).

8. Інтернет-ресурс зі створення QR-кодів. URL: https://www.the-qrcode-generator.com/ (дата звернення: 16.01.2020).

9. Інтернет-ресурс зі створення QR-кодів. URL: http://www.qrstuff.com/ (дата звернення: 16.01.2020).

10. Інтернет-ресурс зі створення QR-кодів. URL: https://www.unitag.io/qrcode (дата звернення: 16.01.2020).

11. Інтернет-ресурс зі створення QR-кодів. URL: https://qrcode.kaywa.com/ (дата звернення: 16.01.2020).

12. Кравчук C. Що таке BYOD? URL: http:// thefuture.news/byod (дата звернення: 16.01.2020).

13. Рашевська Н. В. Технології мобільного навчання / Н. В. Рашевська, В. В. Ткачук // Педагогіка вищої та середньої школи. - 2012. - Вип. 35. C. 295-301.

Дата надходження до редакиї: 13.01.2020 p.

Віталія ТИМЧИНА, старший викладач кафедри природничо-математичної освіти Рівненського ОІППО

\title{
НОВІ ПЕРСПЕКТИВИ ОСВІТНЬОГО ПРОЦЕСУ: ВІРТУАЛЬНА ТА ДОПОВНЕНА РЕАЛЬНІСТЬ
}

\footnotetext{
У статті розглянуто поняття віртуальної, доповненої та змішаної реальності. Виокремлено різні типи систем віртуальної реальності, розмежування яких лежить у площині способів та режимів їхньоі взаємодії з користувачем. Розкрито доиільність використання технологій віртуальної і доповненої реальності як методів активного навчання з метою вивчення різних предметів та описано деякі освітні проєкти з використанням віртуальної технології. Проаналізовано переваги та недоліки використання означеної технологї в освітньому процесі.

Ключові слова: віртуальна реальність (VR), доповнена реальність (AR), змішана реальність, відеонакладання, система занурення, кіберпростір, тривимірна графіка.
}

В статье рассмотрено понятие виртуальной, дополненной и смешанной реальности. Выделень различные типы систем виртуальной реальности, разграничение которых лежит в плоскости способов и режимов их взаимодействия с пользователем. Раскрыто иелесообразность использования технологий виртуальной и дополненной реальности как метода активного обучения для изучения различных предметов и описаны некоторые образовательные проекты с использованием виртуальной технологии. Проанализированы преимущества и недостатки данной технологии в образовательном проиессе.

Ключевые слова: виртуальная реальность (VR), дополненная реальность (AR), смешанная реальность, видеоналожение, система погружения, киберпространство, трехмерная графика. 
The article defines the concept of virtual, augmented and mixed reality. It identifies different types of virtual reality systems, the distinction of which lies in the plane of ways and modes of their interaction with the user. The paper analyzes the current state of virtual reality as a new level of the information technology development and its impact on all spheres of society. The main features by which the 3D-system of visualization can be classified as "virtual reality» are named as well.

New opportunities and great educational potential of virtual reality technologies for teaching people with special educational needs were noted.

The virtualization of education opens up fundamentally new possibilities for solving two of the most important and relevant problems of nowadays: the increasing of accessibility of qualified education and the continuation of the educational process throughout the human life, which is already a universally recognized requirement, that has been already recognized in UNESCO documents.

Variety of elements of virtual reality are characterized as the cyberspace, three-dimensional graphics, simulation, 3D-tour and virtual panorama.

It has been noticed that the use of virtual and augmented reality technologies as the method of the active learning can be effectively used for visual demonstrations, which allow immersing students in the process of study and increasing the level of learning of their educational material.

The article describes some educational projects of using the virtual technology to teach various subjects. In addition, a selection of mobile applications of using the technologies of virtual and augmented realities that can be used at the lessons of astronomy, physics, geography, ecology, history, archeology, biology, anatomy, chemistry, work training, algebra and the beginnings of analysis and geometry, physical culture, fine arts and at elementary school. The advantages and disadvantages of $V R$ technology in the educational process are analyzed.

Key words: virtual reality $(V R)$, augmented reality $(A R)$, mixed reality, video overlay, immersion system, cyberspace, three-dimensional graphics.

Третє тисячоліття яскраво демонструє нам швидкоплинний розвиток новітніх технологій, штучного інтелекту та нового мислення. Такі зміни вказують нам на нові траєкторії розвитку освіти. «Школа має бути в авангарді суспільних змін», - зазначено в Концепції Нової української школи. В умовах надстрімкого розвитку науки, техніки й технологій змінюються і підходи до форм, методів та засобів організації навчання. Ми вважаємо, що для дітей покоління Z використання віртуальної та доповненої реальності iз сучасними засобами навчання стане тим магнітом, який буде утримувати зосередження їхньої уваги на навчанні завдяки елементам гри чи дослідження.

Аналіз наукових досліджень та публікацій. Дослідженням можливостей віртуальної та доповненої реальності займалися Дж. Байленсон, О. Войскунський, С. Карелов, П. Кенні, Н. Лібераті, П. Мілграм, Г. Ріва, В. Селіванов, Л. Селіванова, М. Слатер, Є. Паулет, Дж. Постіл, Р. Берінгер, П. Донеллі, С. Фейнеpa, С. Жульєр, Б. Макінтайр та ін. Технологічним інструментам, які дають змогу впровадити доповнену реальність та віртуальну реальність до медіасередовища, присвячені праці О. Висоцької, К. Віслянської, Н. Гринник, Р. Келлана-Джонса, О. Коструби,
В. Малинки, М. Нитки та ін. Водночас В. Цвєтков розглядає віртуальну реальність як нову форму подання і моделювання реальності, на основі якої можна отримати нове просторове знання [5, с. 35]. На думку вченого, віртуальна реальність - модельне багатовимірне (3D) навколишнє середовище, яке утворюється комп'ютерними засобами та реалістично реагує на взаємодію з користувачами. Однак, незважаючи на означене вище, механізми використання віртуальної реальності в освіті залишаються недостатньо вивченими, що й зумовило написання нами представленої статті.

Мета статті - охарактеризувати доцільність використання віртуальної та доповненої реальності в освітньому процесі сучасного закладу загальної середньої освіти.

Виклад основного матеріалу. Віртуальна реальність (від англ. Virtual Reality, скорочено - VR) - світ, створений за допомогою використання технічних засобів, який передається людині через іiі відчуття: зір, слух, нюх, дотик тощо. Іншими словами, це комп'ютерна тривимірна модель фізичного середовища, в якому користувач може рухатися та взаємодіяти з об'єктами, що в ньому містяться [8, с. 64-68]. Віртуальна реальність (або ж віртуальне середовище) імітує не лише дію, а й реакції на неї. Людина занурюється туди за допомогою спеціальних пристроїв (найчастіше - VR-шоломів) і не може бачити те, що відбувається в реальному світі.

Доповнена реальність (від англ. Augmented Reality, скорочено - AR) - технологія інтерактивної комп'ютерної візуалізації, що дає змогу доповнити зображення реального світу віртуальними елементами та відображає його на екрані пристрою. Ця технологія формує здатність сприйняття користувачів у реальному світі, а не створює альтернативний світ. Доповнена реальність не змінює середовище людини, а лише доповнює його штучними елементами. Ключовим $є$ те, що цифровий контент не прикріплений до простору. Алгоритм роботи технології доповненої реальності полягає в тому, що відеокамера мобільного пристрою зчитує зображення, яке містить мітки (маркери), та передає відеосигнал у комп'ютер (смартфон, планшет). Спеціальна програма опрацьовує отриманий сигнал та після цього на екрані пристрою накладає на зображення реального об'єкта віртуальний об'єкт. Роль віртуальних об'єктів можуть виконувати тексти, посилання на сайти, світлини, об'ємні елементи, звуки, відео тощо [3, с. 79].

Змішана реальність (від англ. Mixed Reality, скорочено - MR) - це оточення, яке створено з прив'язкою до реального світу. У змішаній реальності в середовище людини додаються віртуальні предмети, які прикріплені до свого місця в просторі для того, щоб спостерігач сприймав їх як реальні [2, с. 207-208].

Існують різні типи систем віртуальної реально$c m i$, розмежування яких лежить у площині способів і режимів їхньої взаємодії з користувачем. Це:

а) системи типу «Вікно у світ» - використовуються сучасні комп'ютерні монітори для відображення візуальної частини кіберсвіту;

б) відеонакладання - за допомогою відеокамери силует користувача накладається на двовимірне зображення, що створюється комп'ютером, унаслідок чого користувач дивиться на екран та бачить свій силует, тобто власне віртуальне тіло в кіберпросторі, яке взаємодіє з віртуальним світом; 
в) системи занурення - досконалі системи віртуальної реальності, що занурюють користувача у віртуальний світ повною мірою, створюючи при цьому відчуття присутності;

г) системи дистаниійної присутності - передбачають з'єднання віддалених сенсорів, розташованих на будь-якому об'єкті в реальному світі 3 оператором-людиною;

г) змімана реальність - об'єднання систем дистанційної присутності й системи, що грунтується на віртуальній реальності, комп'ютерне зображення якої генерується завдяки інформації, що виводиться датчиками систем дистанційної присутності.

Основними ознаками, за якими система 3D-візуалізації може бути віднесена до класу віртуальної реальності, є такі:

- стереоскопічне зображення;

- зображення погоджується 3 координатами зорових сенсорів;

- систему оснащено двонаправленим інтерфейсом (вхід - координати зорових сенсорів, вихід зображення);

- час обновлення зображення у відповідь на зміни координат сенсорів не перевищує 1/16 секунди $[7$, с. $1-8]$.

Використання мобільних технологій в освітньому процесі все частіше впроваджується в освітню практику. Адже смартфони і планшети - це мобільні персональні комп'ютери із сенсорним екраном i виходом у мережу Інтернет, які мають фото- і відеокамеру, мікрофон, датчик GPS, операційну систему 3 можливістю встановлення різноманітних додатків. Зважаючи на це, природним є свідоме включення мобільних пристроїв учнів до освітнього процесу, що $є$ сутністю освітньої моделі BYOD («Bring Your Own Device» - принеси свій власний пристрій) [9]. Підхід BYOD відкриває перед освітою можливості використання значної кількості сучасних інформаційних технологій, застосування яких в освітньому процесі може змінити його докорінним чином.

Технологія віртуальної реальності дає змогу користувачеві з особливими освітніми потребами отримувати доступ та використовувати такі ж навчальні матеріали вдома, як і в реальному закладі освіти. У зв'язку з цим варто відзначити нові можливості та неабиякий освітній потенціал технологій віртуальної реальності для навчання, зокрема людей з особливими освітніми потребами.

Віртуалізація системи освіти активно впроваджується в розвинених країнах світу впродовж останнього десятиліття. Стимулами для цього є три основних чинники:

- підвищення вимог до рівня кваліфікації робочої сили у зв'язку з технологічним удосконаленням сучасного виробництва і сфери обслуговування населення;

- перехід промисловості на дрібносерійне виробництво внаслідок швидкої змінюваності моделей, що вимагає оперативної перепідготовки персоналу значної кількості компаній;

- усе більше усвідомлення суспільством цінності якісної освіти як особистісного та національного надбання.

Крім того, віртуалізація освіти відкриває принципово нові можливості для вирішення двох найважливіших та найактуальніших проблем сучасності:

- підвищення доступності якісної освіти;
- безперервності процесу освіти протягом усього життя, що на сьогодні є загальновизнаною вимогою, проголошеною в документах ЮНЕСКО.

Віртуальна реальність в освіті дає змогу:

- проводити телемости, відеоконференції;

- створювати електронні освітні ресурси у форматі 3D;

- розробляти презентаційні та інформаційні 3D-матеріали;

- створювати музеї, лабораторії, планетарії;

- візуалізувати більш складні об'єкти та фізичні явища.

Більш детально зупинимося на різновидах елементів віртуальної реальності:

- кіберпростір - інтерактивне інформаційне середовище, яке функціонує за допомогою комп’ютерних систем;

- тривимірна графіка - зображення, які включають побудову геометричної проєкції тривимірної моделі;

- симуляція - режим створення проєкту, який вимагає залучення користувача та додає блоки для натиснення маніпулятором миші, додає надписи 3 відображенням поточного стану користувача або підказками;

- 3D-тур - сукупність декількох віртуальних панорам, між якими можна переміщуватися, використовуючи спеціальні переходи. Відвідувачеві віртуального туру дається можливість переходити 3 одного приміщення в інше, орієнтуючись за картою (навігатором), де він перебуває в цей момент;

- віртуальна панорама - фотореалістичний спосіб подання реальності, що дозволяє користувачеві переміщуватися у віртуальному просторі. Віртуальна панорама створює ілюзію присутності в тривимірному просторі.

Доповнена реальність додає відчуттів, що надійшли з реального світу, уявних об'єктів, зазвичай із допоміжними інформативними властивостями.

Імітація тактильних відчуттів застосовується для вирішення завдань віртуального прототипування й ергономічного проєктування, створення різних тренажерів, дистанційного керування роботами, зокрема в мікро- й наносистемах створення віртуальних скульптур [2, с. 209-212].

Використання технологій віртуальної та доповненої реальності як методу активного навчання може ефективно застосовуватися для наочних демонстрацій, що дають змогу занурити учнів у досліджуваний процес і підвищити рівень засвоєння ними навчального матеріалу.

Варто зауважити, що неабиякої популярності в Європі набув проєкт «CLASSVR». Його творці пропонують не лише повноцінний набір засобів віртуальної реальності (пристрій + програмне забезпечення), а й комплексне рішення, що дозволяє реалізувати масове навчання. За допомогою такого набору можна здійснювати навчання не тільки в невеликих групах, а й у справжніх навчальних класах із великою кількістю учнів.

На сьогодні кількість освітніх проєктів із використанням віртуальної технології постійно зростає [4, с. 316-317]. Це, наприклад: «LABSTER» (дає змогу здійснювати різноманітні експерименти, створюючи ефект присутності); «EXPEDITIONS PIONEER PROGRAM» (проведення віртуальних екскурсій різноманітними куточками земної кулі); 
«ER VR (VIRTUAL REALITY MEDICAL TRAINING SIMULATION)» (навчальний програмний засіб для лікарів, що використовується з метою тренування їхніх умінь у надзвичайних ситуаціях); «THE APOLLO 11 VIRTUAL REALITY EXPERIENCE» (віртуальна гра для керування польотом на Місяць); «Colosseum VR» (проєкт для перенесення в Стародавній Рим, допомагає вивченню історіï); «Mezo VR» (відтворення історії цивілізації, перегляд археологічних розкопок); «zSpace» (за допомогою інтерактивної ручки можна здійснювати огляд людського тіла, молекулярної сітки); «EligoVision» (проєкт, що допомагає виконувати різноманітні завдання (модернізація міста, візуалізація об'єкта тощо)); «Melchemistry» (додаток для проведення хімічних дослідів); «GoogleExpeditions» (відвідування будь-якого куточка Землі, поєднання віртуальної екскурсії з реальним світом).

Проєкт X. Кауфмана i Б. Мейєра «Physics Playground», орієнтований на моделювання фізичних експериментів у галузі механіки, має величезну кількість інструментів для аналізу впливу сили, маси, траєкторії, швидкості та інших характеристик об'єктів фізичного світу та дозволяє детально вивчати процеси, що відбуваються, й експериментувати в тривимірному віртуальному просторі, виключаючи витрати на оригінальні випробування [6].

Так, у галузі хімії програми AR i VR дають змогу вивчати будову атомів і молекул, проводити зазвичай досить дорогі або ж небезпечні досліди, спостерігати за хімічними перетвореннями тощо. У біології за їхньою допомогою відбувається масштабування до розміру органів, клітин або навіть молекул ДНК. Завдяки інтерактивним можливостям програм можна спостерігати як за статичними, так і динамічними процесами, наприклад, реплікацією ДНК.

Під час вивчення математики за допомогою технології AR можна візуалізувати різноманітні геометричні поверхні. При цьому з'являється можливість вивчати поверхню як реальний об'єкт, який бачимо перед собою, а не на екрані комп'ютера чи книги, змінювати параметри в реальному часі та спостерігати за результатом. Інтерактивна зміна параметрів сприяє кращому розумінню структури рівнянь і форми тривимірних поверхонь.

Нижче подамо вибірку мобільних додатків із використанням технологій віртуальної та доповненої реальності, які варто використовувати на уроках:

- початкова школа: «Quiver», «Augmented Reality Solar System», «4D Zoo AR», «Dinosaur Life 4D», «Експедиції», «Google Arts \& Culture», «Skyscrapers $\mathrm{AR} »$, «Bridges AR», «Augment», «WowBox AR», «AR Flashcards - Animal Alphabet»;

- астрономія: «Universe Sandbox 2», «Apollo 11 VR», «Solar System AR», «AR Circuits 4D», «Augmented Reality Solar System», «Spacecraft 3D»;

- географія, екологія: "Google Earth VR», «My Way VR», «AR Planet Earth | Geography», «Google Arts \& Culture», «CleverBooks Geography»;

- історія, археологія: "The VR Museum of Fine Art», «Titanic VR», «King Tut VR», «Civilisations AR», «Google Arts \& Culture»;

- біологія, анатомія: «3D-Organon VR Anatomy», «The Body VR», «Anatomy 4D», «Surgeon Simulator: Experience Reality», «Anatomyou VR», «AR-3DScience» «Virtual Reality Cellscape Experience», «InMind 2 VR»;
- фізика та астрономія: «PhysicsPlayground», «Skyscrapers AR», «Electricity AR», «Bridges AR», «AR-3D-Science», «Atom Visualizer», «Electric Circuit AR»; - хімія: «MEL Chemistry VR», «AR-3D-Science», «LiCo.STEM»;

- алгебра $i$ початки аналізу та геометрія: «VR MATH», «VR Geometry Tutor», «CleverBooks Geometry»;

- трудове навчання: «Job Simulator», «250 ремісничих проєктів ручної роботи»;

- фізична культура: «The Thrill of the Fight VR Boxing», «VR Soccer Header», «AR Sports Basketball»; - образотворче мистеитво: «Tilt Brush», «Dreams», «Civilisations AR», «Google Arts \& Culture».

Варто також виокремити можливості використання фото та відео $360^{\circ}$, наприклад, ресурс airpano.com. Вони відповідають частковому зануренню у віртуальну реальність і мають мінімальні вимоги до технічних характеристик шолома віртуальної реальності. Такий тип цифрового контенту може мати дуже високу реалістичність завдяки тому, що він створюється за допомогою фото- чи відеокамери на $360^{\circ}$ і його доцільно використовувати для показу виставок музеїв, вулиць туристичних міст, різноманітних природних середовищ, інтер'єру або місць, де більшість об'єктів є статичними; для спостереження за перебігом процесів, природними явищами, культурними подіями тощо. Зауважимо, що реалізовувати технологію доповненої реальності допомагають і QR-коди.

Результати наукових досліджень [10] щодо застосування технологій доповненої реальності в процесі навчання визначають низку переваг, а саме:

- наочність;

- економія часу і коштів на конкретний освітній процес (наприклад, учні мають можливість використовувати необмежену кількість хімічних реактивів для дослідів або інших ресурсів);

- інтерактивність (можна не лише спостерігати за тим, що відбувається, від першої особи в режимі 3D, a й активно брати участь в освітньому процесі, проводити експерименти на мікро- і макрорівнях, отримувати різноманітні результати залежно від способу дії учня);

- повне занурення в процес навчання завдяки 3D-візуалізації та елементам гейміфікації;

- легкість пояснення складних для розуміння явищ та предметів;

- зрозумілість та цікавість навчальних матеріалів для учнів;

- безпосередній, а не теоретичний, досвід;

- середовище, яке сприймається людиною через органи чуття;

- менший вплив відволікаючих факторів, що заважають сприйняттю інформації;

- екологічність (зазвичай технології доповненої реальності не шкодять довкіллю та є більш екологічними ніж традиційні мультимедійні засоби);

- безпека (користувачі можуть проводити небезпечні для життя наукові експерименти, вчитися літати на будь-яких літальних апаратах без ризику для їх життя та життя інших).

Однак, незважаючи на означене вище, серед людей старшого покоління іноді можна почути думку про віртуальну залежність та небезпеку «піти й не повернутися» 3 віртуального світу. При цьому аналіз, здійснений О. Войскунським відносно різниці між станом присутності (основою віртуальної реальності) та зміненим станом свідомості (дія хімічних препаратів, гіпнозу тощо), 
чітко засвідчив, що перебування у віртуальній реальності, на відміну від зміненого стану свідомості, не характеризується відчуттями «виходу з тіла», роздвоєної свідомості, присутності «вищого розуму», не знижує ступінь рефлексії, не викликає неадекватності мислення та не призводить до втрати волі [1].

Зрозуміло, що означений метод навчання в жодному разі не замінює реальну практику, а лише сприяє максимальній підготовці до неї.

Крім того, варто розглянути основні недоліки застосування технологій доповненої реальності.

- складність створення моделей: досвід користувача у віртуальній реальності значним чином залежить від ступеня занурення його у віртуальний світ та ступеня опрацювання віртуального середовища, тому на сьогодні створення навчальних матеріалів зміненої реальності $€$ процесом досить трудомістким як із погляду людських ресурсів, так і обчислювальних потужностей. Необхідно не лише володіти глибокими знаннями про суть процесу / об'єкта для вивчення, а й якісно розробити навчальну модель у спеціалізованому середовищі;

- обмеженість: необхідно розуміти, що при всій реалістичності й наочності, ті матеріали віртуального світу, які учні можуть використовувати у своїй освітній діяльності, - це моделі реального світу. Отже, вони мають бути добре вивченими і перевіреними. Таким чином, не вивчені / не до кінця вивчені процеси в реальному житті розглядати за допомогою зміненої реальності неможливо;

- недостатній рівень підготовки більшості вчителів: фахівцям доцільно проводити навчання (тренінги, майстер-класи) з означеного питання для вчителів закладу;

- високий рівень иін на апаратне забезпечення $i$ розробку ПЗ;

- недосконалість сучасних систем віртуальноі реальності, погіршення самопочуття користувачів y проиесі тривалого використання иієї технології: значна кількість користувачів скаржиться на нездужання, нудоту і головний біль після певного часу перебування у зміненій реальності. Відбувається це у зв'язку з різницею в якості зображення та в часі між поворотом голови й відображенням нової картини віртуальної реальності. Аби цього не було, вся система та окуляри зміненої реальності мають показувати картинку віртуального світу із частотою не менше ніж 90 кадрів у секунду і мати затримку в часі від повороту голови, допоки не 3'явиться нова картинка, не більше 20 мілісекунд. На сьогодні виробники засобів віртуальної реальності працюють над вирішенням цього завдання. Аби уникнути негативних наслідків, вони рекомендують робити перерву щонайменше кожних 30 хвилин занурення у віртуальний світ [6].

Висновки. Отже, зважаючи на розглянуте вище, можемо зробити такий висновок: ключовими завданнями модернізації сучасної української школи залишаються такі: орієнтація змісту освіти на швидкий розвиток новітніх технологій, штучного інтелекту, нового мислення; підготовка працівників, які вміють критично мислити, можуть створювати новий продукт, зокрема електронний, для промисловості; оновлення структури, перепідготовка кадрового складу педагогічних i науково-педагогічних працівників, відповідність матеріально-технічної бази потребам ринку праці з упровадженням в освітній процес сучасних технологій. При цьому технології віртуальної реальності містять величезний потенціал для вирішення завдань освітнього процесу. Їх використання впливає на всі компоненти пізнавальної активності учнів. Водночас школярі не лише навчаються роботі 3 цифровими інструментами, а й набувають досвіду досліджень, у них розвиваються метапредметні навички, стрімко формуються універсальні навчальні дії, розширюється інформаційне середовище для пізнавальної та освітньої діяльності. Завдяки новизні та оригінальності здобувачі освіти значно підвищують мотиваційний компонент власної діяльності.

Таким чином, застосування карток, енциклопедій, художніх та навчальних книг, посібників, розмальовок, кубиків тощо разом із додатками доповненої реальності значно збільшить мотивацію до навчання, підвищить рівень засвоєння інформації шляхом різноманітності та інтерактивності ¥іi візуального представлення, дасть змогу перенести частину науково-дослідної роботи учнів у площину дистанційного навчання, поліпшить середовище навчання, а також сприятиме формуванню дослідницьких умінь, розвитку пам'яті, уяви, мислення та емоційного інтелекту.

\section{СПИСОК ВИКОРИСТАНОЇ ЛІТЕРАТУРИ}

1. Войскунский А. Е. Психология и интернет / А. Е. Войскунский. - Москва : Акрополь, 2010. - 439 с.

2. Климнюк В. Є. Віртуальна реальність в освітньому процесі / В. С. Климнюк // Збірник наукових праць Харківського національного університету Повітряних Сил. - 2018. - № 2. - С. 207-212.

3. Лешко К. В. Формування професійно-пізнавальної активності майбутніх педагогів 3 використанням засобів доповненої реальності / К. В. Лешко, Л. Л. Рикова // New computer technology. - 2019. № 17. - С. 76-81.

4. Трач Ю. В. VR-технології як метод і засіб навчання / Ю. В. Трач // Освітологічний дискурс. - 2017. № 3-4. - С. 309-322.

5. Цветков В. Я. Виртуальное моделирование / В. Я. Цветков // European Journal of Technology and Design. - 2016. - Vol. 11. - Is. 1. - C. 35-44.

6. Чарченко П. С. Погляд крізь майбутнє: навчати, використовуючи віртуальну реальність. URL: http://dovkillya.org.ua/images/tekhnologiji-integratsijizmistu-osviti-vipusk-11.pdf\#page=140 (дата звернення: 20.12.2019).

7. Фореман Н. Прошлое и будущее 3-D технологий виртуальной реальности / Н. Фореман, Л. Коралло // Научно-технический вестник ИТМО. - 2014. № 6 (94). - C. 1-8.

8. Bailenson J. N. Avatars / J. N. Bailenson // Encyclopedia of Human-Computer Interaction. Berkshire : Publishing Group : Great Barrington, MA, USA. - 2004. - P. 64-68.

9. Bring your own device - Wikipedia. URL: http:// goo.gl/A8YIkz.

10. Kamalika Dutta / Augmented Reality for E-Learning. URL: https://www.researchgate.net/ publication/304078112_Augmented_Reality_for_ELearning. - Title from the screen.

Дата надходження до редакиіï: 28.12.2019 p. 